\title{
Optimization of Aluminum Sand Casting process parameters on RSM and ANN methods
}

DOI:10.36909/jer.12949

\author{
G. Mahesh", D. Valavan*, N. Baskar*, S.T.Jayasuthakar ${ }^{* *}$, S. Saravanan ${ }^{* * *}$ \\ *Department of Mechanical Engineering, Saranathan College of Engineering, Trichy,- \\ 620012, India. \\ ** Department of Mechanical Engineering, University College of Engineering, \\ Thirukkuvalai-610204, India. \\ *** Department of Mechanical Engineering, K.Ramakrishnan College of Technology, \\ Trichy-621112, India. \\ ***Correspondence: nanosaran007@gmail.com
}

\begin{abstract}
Sand casting is one of the best processes to produce a product to satisfy the customer requirements. The prime advantages of choosing the sand casting technique are perfect dimensional geometry, development of pattern is easy, production rate is high, and solidification time is low when compared to other casting techniques. The main purpose of sand casting is to produce a product with better quality in low cost. The properties of the green sand are based on the sand composition and the most important parameters in the preparation of moulding sand are green strength, moisture content and clay content. In this work, the silica oxide is blended in green sand with various compositions for cope box. The various compositions of sand parameters are experimentally investigated by using Response Surface Methodology (RSM). The results of sand parameters are compared with Artificial Neural Network (ANN) analysis. The blending of $9.2 \% \mathrm{SiO}_{2}$ with green sand is very suitable for this casting process. The blending of 9.2\% $\mathrm{SiO}_{2}$ with green sand is very suitable for this casting process. The effect of $\mathrm{SiO} 2$ blending with green sand, the initial raw material is reduced up to $25 \%$ of volume without casting defects.
\end{abstract}


The hardness value increased up to $22 \%$ and the surface roughness decreased up to $12 \%$ by varying the percentage of $\mathrm{SiO} 2$ in green sand.

Keywords: $\mathrm{SiO}_{2}$, Green sand, RSM, ANN

\section{INTRODUCTION}

Moisture content is one of the most important properties of sand preparation. The moulding sand property plays an important role of escaping the gases during the solidification process. The foundry industries produces aluminum, cast iron, brass and gun metal in a huge volumes. The researchers are discussed for improving sand casting process with respect to sand parameters, riser design, optimization techniques etc. Priyank et al [1] were investigated the sand casting process parameters by using DOE and ANN and also reported that the vent holes play crucial role in evasion of exhaust gasses during solidification of casting. The possession of the moisture content and properties of yola sand were determined by Paul [2]. Investigation of the yola natural sand was done for the variations in range of moisture content from 1 to $9 \%$. For this experimental investigation, the author concluded that optimum results were moisture content of $5 \%$ and $118.6 \mathrm{KN} / \mathrm{m}^{2}$ compressive strength. In sand casting process, the thermal behavior of casting/chill material was investigated by Farzaneh et al [3] and concluded that the role of temperature in sand casting process has a major impact. The optimization of $\mathrm{CO}_{2}$ casting process was calculated by Noorul Haq et al [4], with the usage of Taguchi method. To obtain final products with high quality, optimization of input parameters were done and it is shows that the various defects that may arise were investigated and the optimum results of the defects were also recommended. In addition to the sand mix at weight percentage components like bentonite clay properties and zircon were selected. The aluminium alloy casting's sand mould properties are the 
targets of the research. For silica sand, the compositions and the physical properties were evaluated by Saliu et al [5] in various industries. The variation in amounts of ingredients, additives and the types of additives influences the properties of the molding sand. Additives like corn flour, coal dust and clay are also included in water and binders.

Mohsen et al [6] investigated the nano composites of aluminum- $\mathrm{Al}_{2} \mathrm{O}_{3}$ in gravity casting. The various fracture tests were conducted experimentally. Ganesh et al [7] investigated the nano silica particles, plays a vital role of casting quality in sand casting process. In this research work, the various optimization techniques like Taguchi and Grey rational analysis result have been analyzed. Mohd Moiz Khan et al [8] discussed the characteristics of green sand. The major mechanical analyses of universal testing compression, shear and impact test are analyzed. The grain finesses number of sand also experimentally investigated by using scanning electron microscope. Production units like Foundry industries in Nigeria Charnnarong Saikew [9] mostly used synthetic sand and imported binders. It has also stated that the foundries use various types of sand for manufacturing mold. The wide use of green sand which is easily available, and shell molding sand, cement bounded sand, dry sand and core sand which are forms of green sand used for special purposes are also analyzed. Factors like permeability, mould hardness, moisture, shatter index, green compressive strength and compatibility control the casting's quality in both the types of molding sands and this was investigated by Himanshu Khandelwal [10]. The above mentioned factors are again dependent on parameters like the grain size, amount of water used and the properties of the binder.

The use of regression equation was developed and optimized in GA and PSO by Surekha [11], the properties like percentage of clay, grain fineness number, and percentage of water of the green sand were analyzed. The control factors like permeability, harness, green compression 
strength were also considered. John et al [12] determined the main parameters such as pouring temperature, mold temperature and runner size of the aluminum alloy, the impact energy and the hardness of the aluminium alloy, and the optimum results were carried out by using the Taguchi experimental design method. Mekonnen et al [13] investigated the casting yield and the surface defects and studied the single blank and double blank aluminium. The chemical compositions of moisture content, clay content, grain size, sprue size, riser size, ramming and thickness and diameter ratio of the blank were considered. Better results for the aluminium blank of this work were obtained with the use of the Taguchi robust method. The environmental conditions on the sand mold properties were investigated by Ramin Meshkabadi [14]. The considered input parameters were mould hardness, permeability and clay content, and the compressive strength was considered as the output parameter. By neuro fuzzy modeling, from day 1 to day 3 with different compositions of the output parameters, the temperature and humidity are calculated and the best compressive strength is obtained while the green sand is recycled. The reused green sand was analyzed by Birru et al $[15,16]$ and a good strength was exhibited with the addition of alumina. The mechanical properties were improved considering the permeability, green and dry compression strength and bentonite content.

Based on the literature review, it is clearly observed that the sand parameters are the important role in sand casting. The various compositions are experimentally analyzed. But the composition of silica with various percentages is not analyzed so far. In this work, the various levels of volume of silica are blended with green sand. 


\section{METHODOLOGY}

\section{Experimental}

The mould boxes divided into two portions such as drag and cope. The drag is in down position and cope is on over the drag box. The drag box is covered with mould cavity and gating system and the cope box is covered with sprue pin and riser. The geometry of mould cavity should solidify faster than the riser. Generally, the $\mathrm{SiO}_{2}$ is one of the best thermal insulators and it will reduce the heat transfer through the green sand. Because of this property, the experimental work is designed by the standard composition of green sand, is prepared for drag box and blended $\mathrm{SiO}_{2}$ with green sand is prepared for cope box. It is clear that the heat transfer rate of drag box is higher than the heat transfer rate of cope box. In this experimentation, the volume and geometry of riser will reduce because of slow heat transfer. The two experimental methods like combination green sand with $\mathrm{SiO}_{2}$ and the design of riser geometry are involved in this work as follows. The major composition of green sand such as moisture and clay content blending with $\mathrm{SiO}_{2}$ are selected with various levels and factors of independent variables. The RSM is selected for this investigation. The RSM designed the input parameters and output responses are shown in the Table 1.

Table 1 Factors and levels of independent variables using RSM

\begin{tabular}{|c|c|c|c|c|}
\hline \multirow{2}{*}{ Factors } & \multirow{2}{*}{ Symbol } & \multicolumn{3}{|c|}{ Levels } \\
\cline { 3 - 5 } & & 1 & 2 & 3 \\
\hline Moisture Content\% & A & 6 & 7 & 8 \\
\hline Clay Content \% & B & 4 & 5 & 6 \\
\hline Silica Oxide $\left(\mathrm{SiO}_{2}\right) \%$ & C & 3 & 6 & 9 \\
\hline
\end{tabular}


The amount of clay content (bentonite binder) of $4-6 \%$ and $\mathrm{SiO}_{2}$ should be maintained from $3-9 \%$ in the green sand as shown in Figure $1(\mathrm{a})$. Generally $\mathrm{SiO}_{2}$ has $1743^{\circ} \mathrm{C}$ of melting point and very less thermal conductivity of $1.4 \mathrm{~W} /(\mathrm{m} . \mathrm{K})$. The concentration of moisture content in the green sand should be within 6-8\% as shown in the Figure 1(b). The experimental work of aluminum cast material with suitable riser conducted by 17 runs is shown in Figure 2 . The geometry of mould cube is $50 \mathrm{~mm}$ square is selected for this investigation. The hardness test was taken from Brinell hardness machine and surface roughness test have been carried out from surface roughness tester are shown in Figure 3(a\&b).
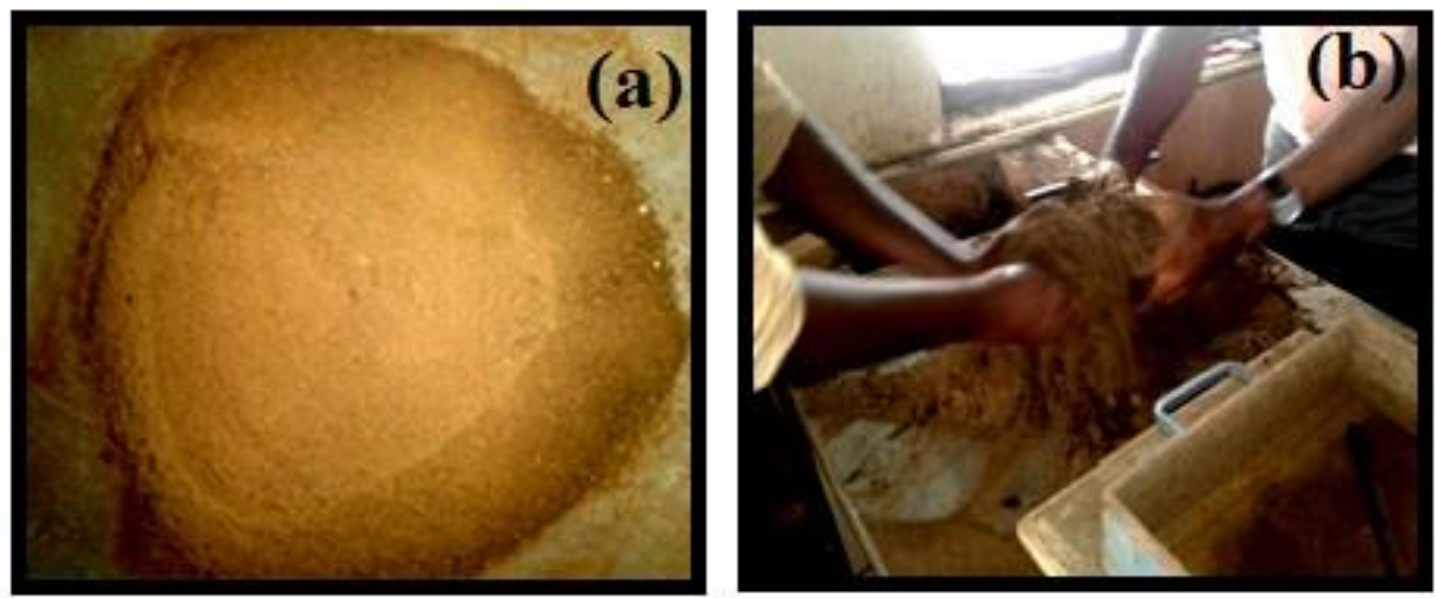

Figure 1 (a) Clay and $\mathrm{SiO}_{2}$ mixer (b) Mixing of moisture content

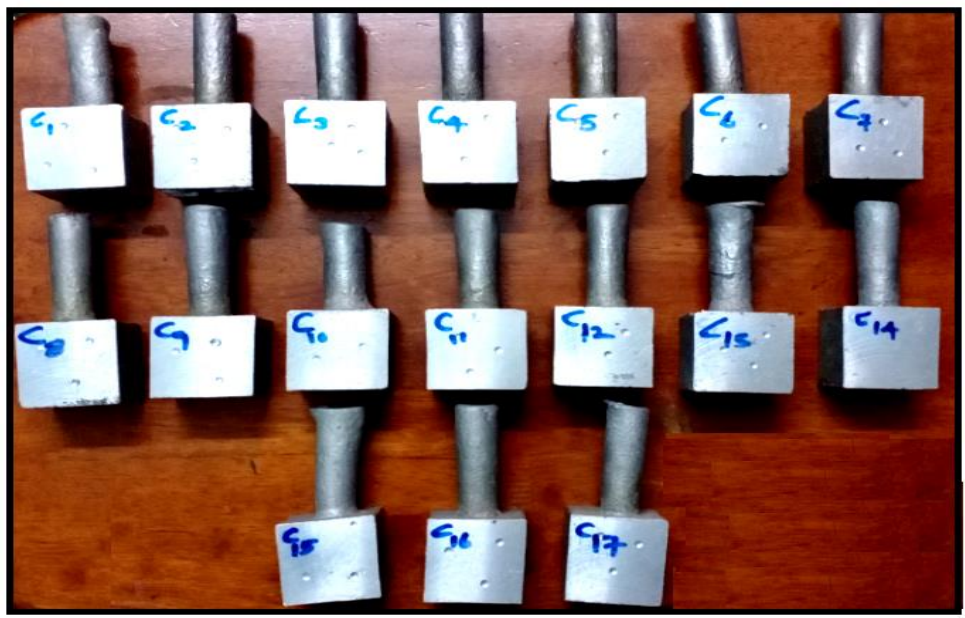


Figure 2 Cast materials for RSM techniques
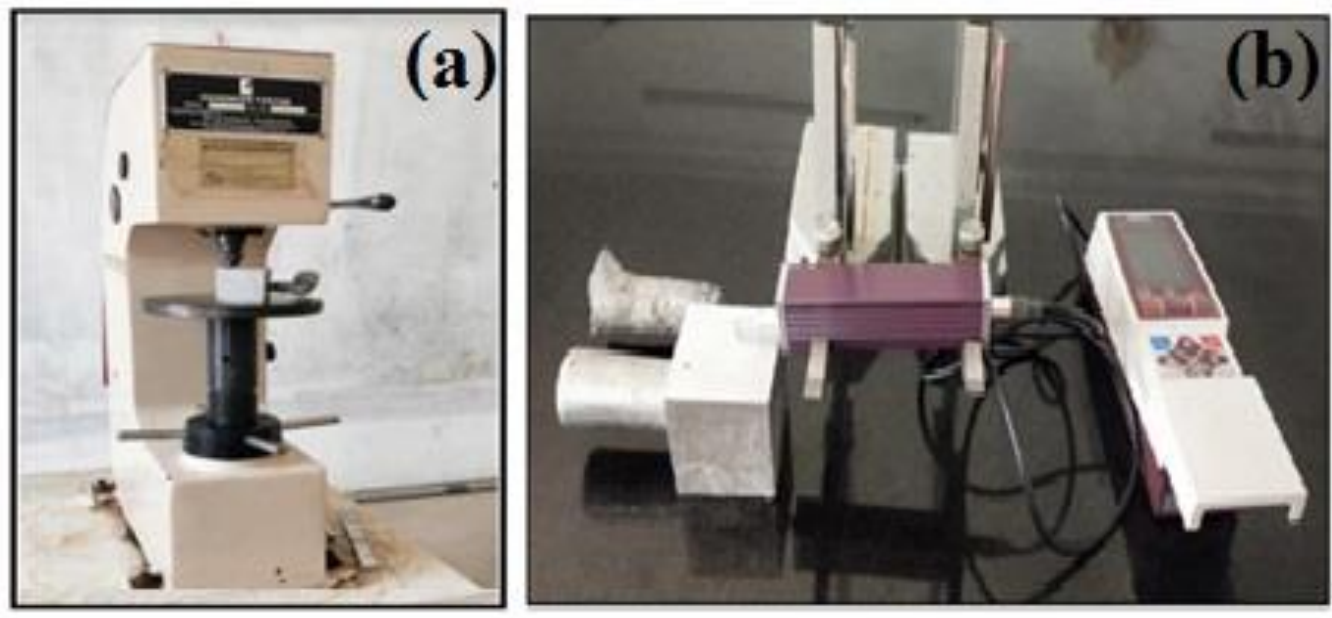

Figure 3 (a) Brinell hardness test machine (b) Surface roughness tester

Modelling of ANN:

The design of expert recommended seventeen sets of experiments on the basis of three factorial designs. The detailed design layout for these experiments is given in the Table 2. It shows various sand compositions such as moisture content, clay content and $\mathrm{SiO}_{2}$.

Table: 2 Design layouts for sand parameters

\begin{tabular}{|c|c|c|c|}
\hline Run & $\begin{array}{c}\text { Moisture } \\
\text { Content (\%) }\end{array}$ & $\begin{array}{c}\text { Clay } \\
\text { Content(\%) }\end{array}$ & $\begin{array}{c}\text { SiO }_{2} \\
\text { Content (\%) }\end{array}$ \\
\hline 1 & 8 & 5 & 6 \\
\hline 2 & 6 & 4 & 6 \\
\hline 3 & 8 & 5 & 9 \\
\hline 4 & 6 & 5 & 3 \\
\hline 5 & 7 & 5 & 9 \\
\hline 6 & 7 & 5 & 9 \\
\hline 7 & 7 & 5 & 9 \\
\hline 8 & 7 & 5 & 6 \\
\hline 9 & 7 & 4 & 3 \\
\hline
\end{tabular}




\begin{tabular}{|c|c|c|c|}
\hline 10 & 7 & 6 & 9 \\
\hline 11 & 7 & 4 & 9 \\
\hline 12 & 7 & 6 & 3 \\
\hline 13 & 6 & 5 & 6 \\
\hline 14 & 8 & 5 & 6 \\
\hline 15 & 7 & 6 & 9 \\
\hline 16 & 8 & 6 & 3 \\
\hline 17 & 7 & 6 & 3 \\
\hline
\end{tabular}

\section{RESULTS AND DISCUSSION}

The input parameters of and output responses are conducted experimental work and it is mentioned Table 3. The output responses of hardness and surface roughness are varied with various input parameters levels. From this technique, the best parameters of the sand preparation are identified. The best optimization techniques of RSM are selected for this investigation. The experimental analysis is on the composition of the moisture content, clay content, $\mathrm{SiO}_{2}$, hardness and surface roughness. This experimentation is carried out for seventeen sets and also suitable riser was implemented as shown in Table 3.

Table 3 Experiment runs for aluminium of various input and output responses

\begin{tabular}{|c|c|c|c|c|c|}
\hline Run & $\begin{array}{c}\text { Moisture } \\
\text { Content (\%) }\end{array}$ & $\begin{array}{c}\text { Clay } \\
\text { Content (\%) }\end{array}$ & $\begin{array}{c}\text { SiO }_{2} \\
\text { Content (\%) }\end{array}$ & $\begin{array}{c}\text { Hardness } \\
(\mathrm{BHN})\end{array}$ & $\begin{array}{c}\text { Surface Roughness } \\
\text { (Microns) }\end{array}$ \\
\hline 1 & 8 & 4 & 6 & 79 & 2.133 \\
\hline 2 & 7 & 5 & 6 & 74 & 2.477 \\
\hline 3 & 8 & 6 & 9 & 81 & 2.199 \\
\hline 4 & 7 & 5 & 3 & 75 & 2.586 \\
\hline 5 & 7 & 4 & 9 & 89 & 2.022 \\
\hline 6 & 7 & 6 & 9 & 87 & 2.099 \\
\hline 7 & 7 & 5 & 9 & 84 & 2.086 \\
\hline 8 & 7 & 5 & 6 & 84 & 2.466 \\
\hline
\end{tabular}




\begin{tabular}{|c|l|l|l|l|l|}
9 & 8 & 5 & 3 & 83 & 2.244 \\
\hline 10 & 7 & 5 & 9 & 87 & 2.086 \\
\hline 11 & 7 & 6 & 9 & 85 & 2.155 \\
\hline 12 & 6 & 5 & 3 & 67 & 2.466 \\
\hline 13 & 6 & 6 & 6 & 68 & 2.466 \\
\hline 14 & 7 & 4 & 6 & 81 & 2.187 \\
\hline 15 & 8 & 5 & 9 & 89 & 2.053 \\
\hline 16 & 6 & 5 & 3 & 69 & 2.577 \\
\hline 17 & 6 & 4 & 3 & 69 & 2.353 \\
\hline
\end{tabular}

The lowest percentage of $\mathrm{SiO}_{2}$ in sand parameter is achieved 67BHN hardness and 2.466 micron surface roughness. The highest thermal insulator of $\mathrm{SiO}_{2}$ content is in cope box only. It is clear that the heat transfer rate of drag box is better than the cope box. The highest percentage of $\mathrm{SiO}_{2}$ in sand parameters are achieved good hardness and low surface roughness. The $\mathrm{SiO}_{2}$ content plays an important role in determining the properties of green sand. For this investigation, the input parameters are moisture content, clay content and $\mathrm{SiO}_{2}$ and the selected output results are hardness and surface roughness applied in ANN techniques. The three dimensional structure of ANN consists of 3 input layers, 4 hidden layers and 2 output layers as shown in Figure 4. 


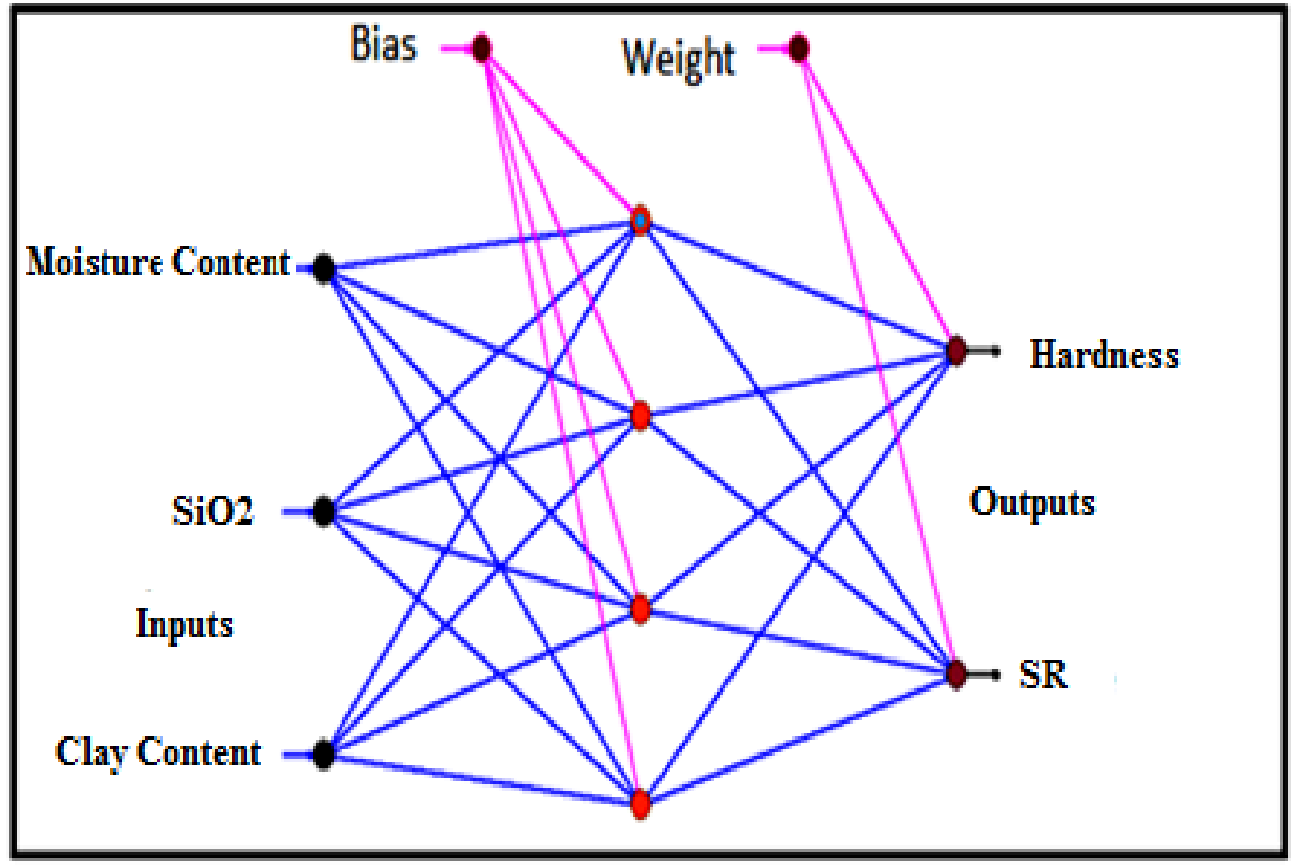

Figure 4 Architecture of ANN for sand parameters

The curve fitting for the hardness and surface roughness of aluminum can be acknowledged as shown in Figure 5. The achieved $\mathrm{R}$ value for hardness is 0.988 and the achieved $\mathrm{R}$ value for the surface roughness is 0.993 respectively.

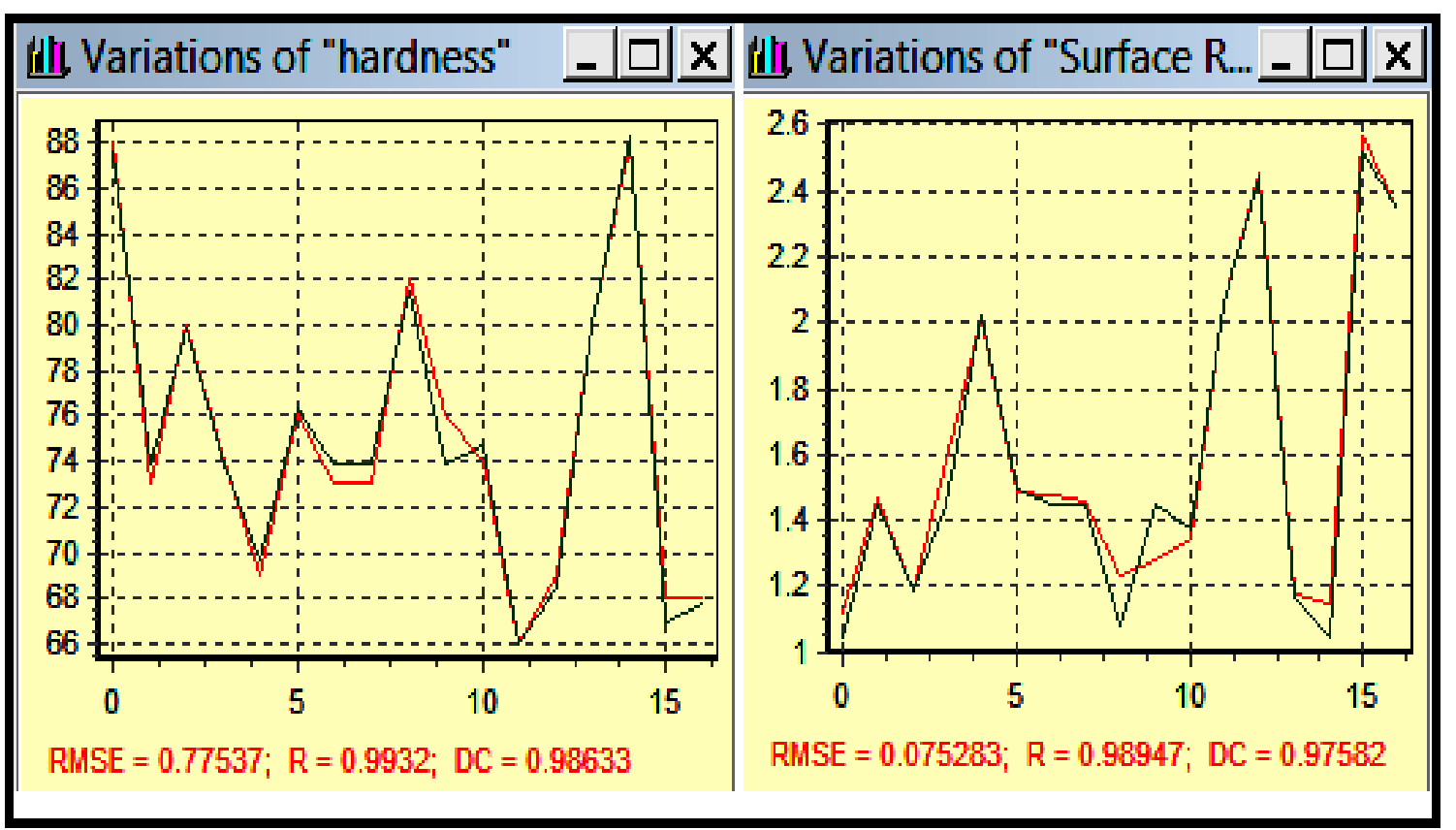


Figure 5 Curve fitting of hardness and Surface roughness for Aluminum

The Figure 6 shows the outcome of moisture content and $\mathrm{SiO}_{2}$ on hardness and surface roughness of aluminum . In the commencement, the hardness is extremely small percentage of moisture content is 6-7 \%. The hardness is improved with respect to boost in moisture content and increase in $\mathrm{SiO}_{2}$. In surface roughness, it is low percentage of moisture content $7.5 \%$. the surface roughness gets varation in moisture content.

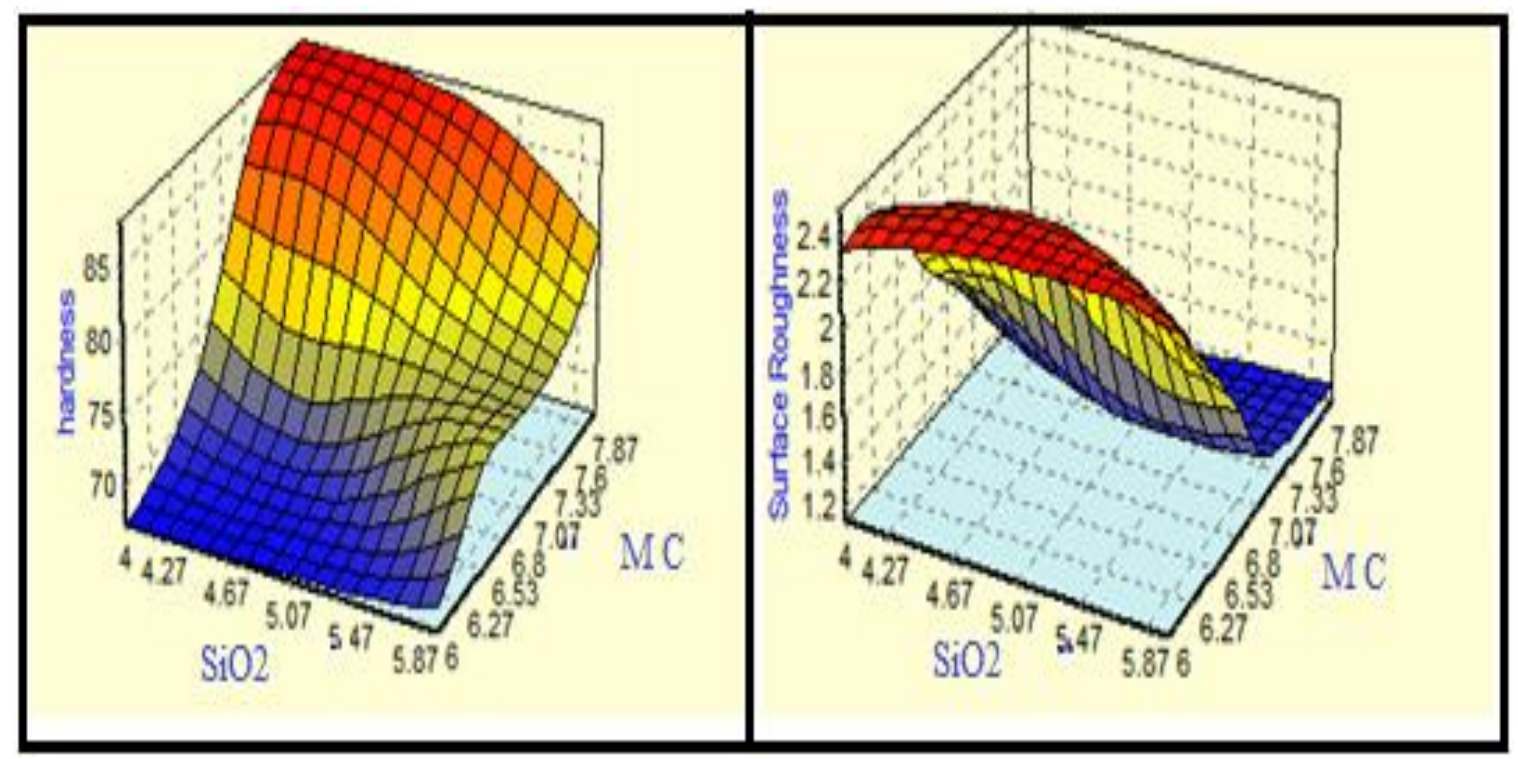

Figure 6 Result of moisture content and $\mathrm{SiO}_{2}$ on hardness and surface roughness of Aluminum

The optimum green sand parameters of hardness and surface roughness are shown in Table 4. The result of ANN shows that the maximum $\mathrm{SiO}_{2}$ content should be in $9.2 \%$ and the moisture content should be in $7.8 \%$. The optimum results of sand parameters are applied in cope box and analyzed best geometry of the riser by ANSYS simulation software. The best result of riser geometry is conducted experimental work.

Table 4Optimum Results of Sand Parameters for Hardness and Surface Roughness of Aluminum 


\begin{tabular}{|c|c|c|c|c|c|c|}
\hline S.No & $\begin{array}{c}\text { Name of the } \\
\text { material }\end{array}$ & $\begin{array}{c}\text { Moisture } \\
\text { Content (\%) }\end{array}$ & $\begin{array}{c}\text { Clay } \\
\text { Content (\%) }\end{array}$ & $\begin{array}{c}\text { SiO } \\
\text { Content (\%) }\end{array}$ & $\begin{array}{c}\text { Hardness } \\
(\mathrm{BHN})\end{array}$ & $\begin{array}{c}\text { Surface } \\
\text { Roughness } \\
\text { (Micron) }\end{array}$ \\
\hline 1 & Aluminum & 7.9 & 4.2 & 9.2 & 95 & 1.821 \\
\hline
\end{tabular}

The various sand parameters of aluminum for RSM, ANN and best riser geometry are compared. The various methods of RSM, ANN hardness which are increases given in Figure 7(a). The other properties of Surface roughness are calculated from RSM, ANN and as shown in Figure 7(b). It is clear that the roughness values are gradually decreased from 2.022 micron to 1.756 micron based on the hardness.
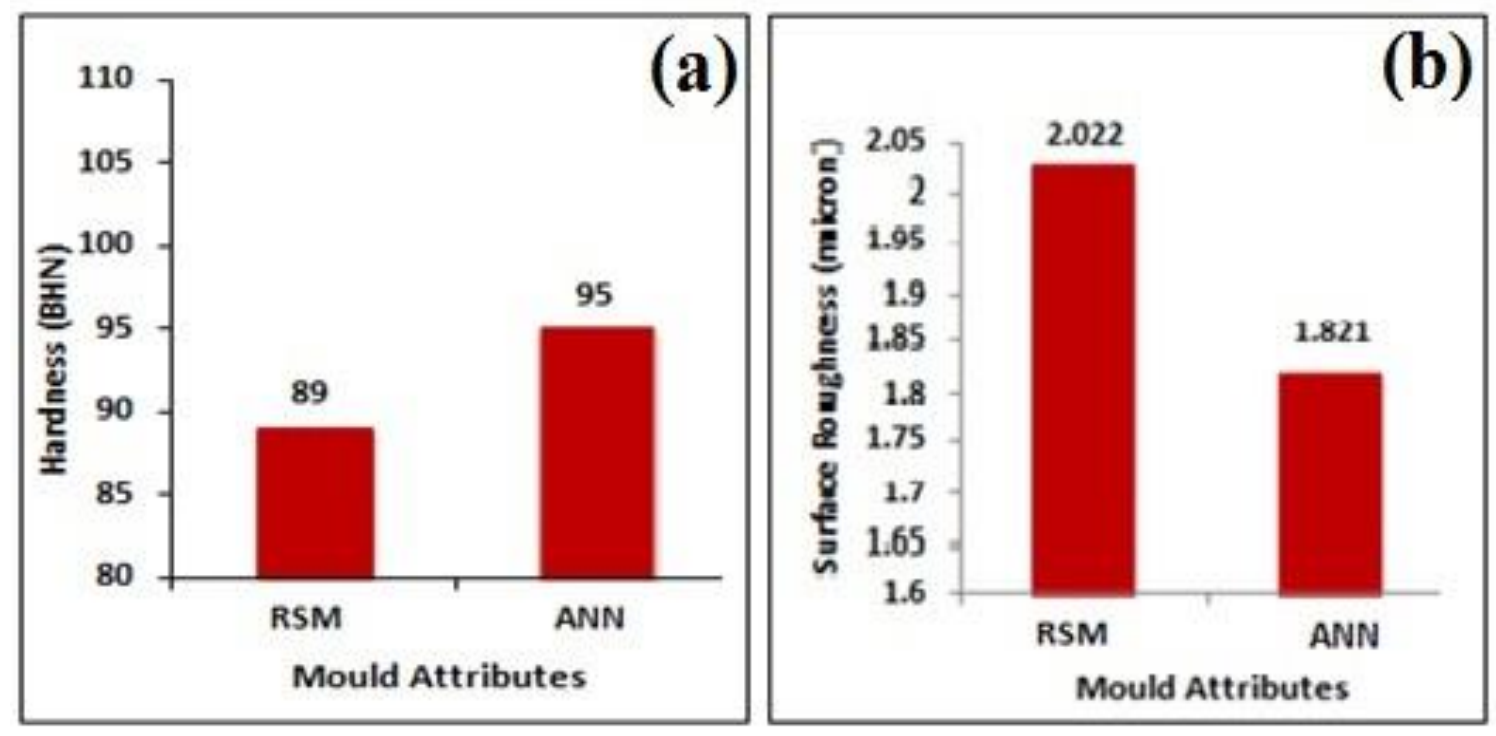

Figure 7 Comparison Results of (a) Hardness (b) Surface Roughness for Aluminum

\section{CONCLUSION}

Green sand is a very important role of heat transfer from the mould cavity and the riser zone in sand casting process. The various combinations of $\mathrm{SiO}_{2}$ with green sand were experimentally investigated. The results of Taguchi orthogonal array, RSM and the 
nontraditional techniques of ANN were analyzed. These methods were used to reduce the cost and time of experiments. The conclusion are derived based on the results and follows

1. It is strongly recommended by the blending of $9.2 \% \mathrm{SiO}_{2}$ with green sand is very suitable for this casting process.

2. The effect of $\mathrm{SiO}_{2}$ blending with green sand, the initial raw material is reduced up to $25 \%$ of volume without casting defects.

3. The hardness value increased up to $22 \%$ and the surface roughness decreased up to $12 \%$ by varying the percentage of $\mathrm{SiO}_{2}$ in green sand.

4. The predicting competence and the accuracy create ANN analytically more practicable tool for foundry industry applications.

5. By mixing of $\mathrm{SiO}_{2}$ with green sand, the riser volume is reduced up to $32 \%$ from raw material.

\section{REFERENCES}

[1]. Priyank, V. Parekh \& Vadher, Dr. J. A. 2015. Optimization of green sand process parameters by Taguchi method and Artificial Neural Network. Journal of Modern Engineering Research.

[2]. Paul De Garmo, E.J.T. Black., Ronald, \& Kohser, A. 2011. Materials and Processes in Manufacturing. Technology and Engineering: 1168.

[3]. Farzaneh, F.M. \& Kokhan, L.S. 2016. Determination of the hardness and the mechanical properties of steel during melting, secondary refining, and continuous casting in an arc-furnace shop. Russian metallurgy: 1203-1206. 
[4]. Noorul Haq, A, S. \& Guharaja, Karuppannan, K. M. 2009. Parameter optimization of $\mathrm{CO} 2$ casting process by using Taguchi method. International Journal on Interactive Design and Manufacturing 3(1): 41-50.

[5]. Saliu Ojo Seidu1 \& Bolarinwa Johnson Kutelu. 2014. Effects of additives on some selected properties of base sand. Journal of Minerals and Materials Characterization and Engineering. 2: 507-512.

[6]. Mohsen Ostad Shabani, Amir Baghani, Ali Khorram, \& Fatemeh Heydari. 2020. Evaluation of fracture mechanisms in Al-Si metal matrix nano composites produced by three methods of gravity sand casting, squeeze casting and compo casting in semisolid state. Silicon.

[7]. Ganesah, R. Chate, G.C. Manjunath Patel,Raviraj, M. Kulkarni, Pavan Vernekar, Anand, S. Deshpande, Mahesh, B. Parappagoudar. 2018. Study of the effect of nanosilica particles on resin-bonded moulding sand properties and quality of casting. Silicon 10: 1921-1936.

[8]. Mohd Moiz Khan, M. Manvendra Singh, G. N. Jadhav, S. M. \& Mahajani, Shashank Mandre. 2020. Characterization of waste and reclaimed green sand used in foundry processing. Silicon 12:677-691.

[9]. Charnnarong Saikaew \& Sermsak Wiengwiset 2012. Optimization of molding sand composition for quality improvement of iron castings. Applied Clay Science 67-68: 26-31.

[10]. Himanshu Khandelwal \& Ravi. 2016. Effect of molding parameters on chemically bonded sand mold properties. Journal of manufacturing process 22: 127-133. 
[11]. Surekha, B. Lalith, K. Kaushik Abhishek, K. \& Panduy. 2012. Multi-objective optimization of green sand mould system using evolutionary algorithms. International Journal of Advanced Manufacturing Technology.

[12]. John, O. Oji, Pamtoks, H. Sunday Omolayo, M. Petinrin Adelana, R. \& Adetunji. 2013. Taguchi optimization of process parameters on the hardness and impact energy of aluminium alloy sand castings. Leonardo Journal of Sciences: $1-12$.

[13]. Mekonnen Liben Nekere \& Ajit Pal Singh. 2012. Optimization of aluminium blanks sand casting for process by using Taguchi Robust Design Method. International Journal for Quality research.6 (1):81- 97.

[14]. Ramin Meshkabadi. 2013. Investigation on the role of moisture content, clay and environmental conditions on green sand mould properties. Journal of Basic and Applied Scientific Research. 3(7): 417-423.

[15]. Birru, A.K. Dharam Singh, L. \& Arun kumar, P. 2014. Enhancement of mechanical properties of recycled green sand by addition of Alumina' 5th International \& 26th All India Manufacturing Technology. Design and Research Conference AIMTDR.

[16]. Measurement: Journal of the International Measurement Confederation, 112, 2017, 53-60. 